\title{
Effects of intraarticular ketamine combined with periarticular bupivacaine on postoperative pain after arthroscopic meniscectomy
}

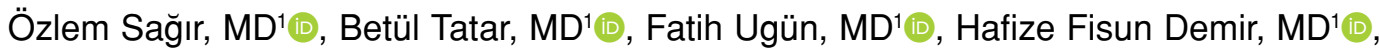

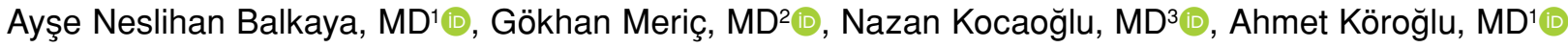 \\ ${ }^{1}$ Department of Anesthesiology and Reanimation, Balıkesir University Faculty of Medicine, Balıkesir, Turkey \\ ${ }^{2}$ Department of Orthopedics and Traumatology, Balıkesir University Faculty of Medicine, Balıkesir, Turkey \\ ${ }^{3}$ Department of Anesthesiology and Reanimation, Kırşehir Ahi Evran University Medical Faculty, Kırşehir, Turkey
}

Arthroscopic knee surgery is one of the most frequently performed orthopedic surgeries. Although being a minimally invasive technique, this surgery may be more painful than expected due to stimulating the bare nerve endpoints and afferent nociceptors, releasing inflammatory mediators such as bradykinin, serotonin and histamine from injured cells. ${ }^{[1]}$ Inadequate management of pain in the postoperative period prolongs hospital stay and delays discharge. ${ }^{[2,3]}$ Many methods are used to prevent or treat pain following arthroscopic knee surgery, including systemic opioids and non-opioid analgesics, central and peripheral nerve blocks, preemptive analgesia, and intraarticular drug administration. ${ }^{[4]}$

Received: April 08, 2020

Accepted: June 09, 2020

Published online: June 26, 2020

Correspondence: Özlem Sağır, MD. Balıkesir Üniversitesi Tıp Fakültesi Anesteziyoloji ve Reanimasyon Anabilim Dalı,

10145 Bigadiç, Balıkesir, Türkiye.

E-mail: ozlemsagir@yahoo.com

Doi: $10.5606 /$ ehc. 2020.75274

Citation: Sağır Ö, Tatar B, Ugün F, Fisun Demir H, Balkaya AN, Meriç $G$, et al. Effects of intraarticular ketamine combined with periarticular bupivacaine on postoperative pain after arthroscopic meniscectomy. Jt Dis Relat Surg 2020;31(3):589-596.

(อ2020 All right reserved by the Turkish Joint Diseases Foundation

This is an open access article under the terms of the Creative Commons Attribution-NonCommercial License, which permits use, distribution and reproduction in any medium, provided the original work is properly cited and is not used for commercial purposes (http://creativecommons.org/licenses/by-nc/4.0/).

\section{ABSTRACT}

Objectives: This study aims to evaluate the effects of two different doses of intraarticular ketamine on visual analog scale (VAS) scores at rest and movement, time to first analgesic requirement, and 24-h morphine consumption in patients undergoing arthroscopic meniscectomy as well as to assess the frequency of postoperative nausea\&vomiting, respiratory depression, pruritus, urinary retention, and constipation and to compare the time to discharge.

Patients and methods: This prospective randomized doubleblind study was performed between August 2013 and August 2014 on 75 patients ( 32 males, 43 females; mean age $46.7 \pm 13$ years; range, 18 to 75 years) with American Society of Anesthesiologists scores of I-II scheduled for unilateral meniscectomy. Patients were randomized to receive $0.5 \mathrm{mg} \cdot \mathrm{kg}^{-1}$ ketamine (group K1), $1 \mathrm{mg} \cdot \mathrm{kg}^{-1}$ ketamine (group K2) or saline (group S) to a total volume of $20 \mathrm{~mL}$ intraarticularly at the end of the surgery. All patients were performed periarticular $10 \mathrm{~mL}$ $0.5 \%$ bupivacaine infiltration. Visual analog scale at rest and during passive knee movement was used to evaluate pain both preoperatively and at postoperative $0,30 \mathrm{~min}$, and 1, 2, 4, 6, 12 , and $24 \mathrm{~h}$. Time to first analgesic requirement and morphine consumption were recorded.

Results: Visual analog scale scores at rest and during movement at postoperative 0 were significantly reduced in group $\mathrm{K} 2$ compared with group $S(\mathrm{p}<0.05)$. The first analgesic requirement time was significantly longer in group K1 $(76.9 \pm 25.2 \mathrm{~min})$ and group $\mathrm{K} 2(93.4 \pm 26.1 \mathrm{~min})$ than group $\mathrm{S}(29.3 \pm 7.1 \mathrm{~min})$. Morphine consumption was lower in group $\mathrm{K} 2$ compared to group $\mathrm{K} 1$ and group $\mathrm{S}$ at postoperative $30 \mathrm{~min}$, and 1 and $2 \mathrm{~h}$. However, 24-h morphine consumption was similar in all groups.

Conclusion: Intraarticular injection of $0.5 \mathrm{mg} \cdot \mathrm{kg}^{-1}$ and $1 \mathrm{mg} \cdot \mathrm{kg}^{-1}$ ketamine for postoperative pain management provided similar analgesic efficacy. However, high dose ketamine more noticeably decreased opioid requirement in the early postoperative period.

Keywords: Intraarticular analgesia, ketamine, knee arthroscopy, periarticular bupivacaine. 
Ketamine has a potent analgesic effect in systemic and peripheral use and interacts with a large number of receptors such as opioid, muscarinic, and $\mathrm{N}$-methyl-D-aspartate (NMDA) receptors. In recent studies, NMDA receptors were demonstrated to play a significant role in peripheral somatic and visceral pain pathways. ${ }^{[5]}$ The presence of NMDA receptors in the knee joint of the rats has been demonstrated and stated that intraarticular administration of ketamine provides adequate analgesia, particularly in arthritic joints. ${ }^{[6]}$ Intraarticular ketamine as a single drug or an adjuvant can be administered to relieve postoperative pain after arthroscopic knee surgery. Controversial results have been published on the analgesic efficiency of intraarticular ketamine depending on the administered dose and the combination drug. ${ }^{[4,7-10]}$ Huang et al. ${ }^{[7]}$ used $0.5 \mathrm{mg} . \mathrm{kg}^{-1}$ intraarticular ketamine on postoperative arthroscopic knee surgery and found no improvement in analgesia. In contrast, Salman et al..$^{[8]}$ have compared the analgesic effect of intraarticular tramadol, magnesium, and ketamine after arthroscopic meniscectomy. They reported that 1 mg. kg-1 intraarticular ketamine reduced additional analgesic requirement and facilitated early mobilization. Ayoglu et al. ${ }^{[9]}$ reported that $0.5 \mathrm{mg} . \mathrm{kg}^{-1}$ intraarticular ketamine improved the analgesic efficacy of both tramadol and ropivacaine on pain management after arthroscopic meniscectomy.

Therefore, in this study, we aimed to evaluate the effects of two different doses of intraarticular ketamine on visual analog scale (VAS) scores at rest and movement, time to first analgesic requirement, and 24-h morphine consumption in patients undergoing arthroscopic meniscectomy as well as to assess the frequency of postoperative nausea \& vomiting (PONV), respiratory depression, pruritus, urinary retention, and constipation and to compare the time to discharge.

\section{PATIENTS AND METHODS}

This prospective, double-blind, single-center randomized controlled study was performed at Balıkesir University Faculty of Medicine, Health Application and Research Hospital between August 2013 and August 2014. In total, 90 patients who underwent arthroscopy during the study period were screened for inclusion. Figure 1 shows the flowchart of patient selection according to the Consolidated Standards of Reporting Trials chart. After screening, 75 patients (32 males, 43 females; mean age $46.7 \pm 13$ years; range, 18 to 75 years) with American Society of Anesthesiologists (ASA) scores of I-II who underwent meniscectomy with unilateral knee arthroscopy were included. Exclusion criteria were the usage of nonsteroidal anti-inflammatory drugs or analgesics during and before surgery, longterm analgesic treatment, prior allergies to any of the drugs, the need of an intraarticular drainage catheter insertion at the end of surgery, traumatic knee injury, and other knee diseases. In all patients,

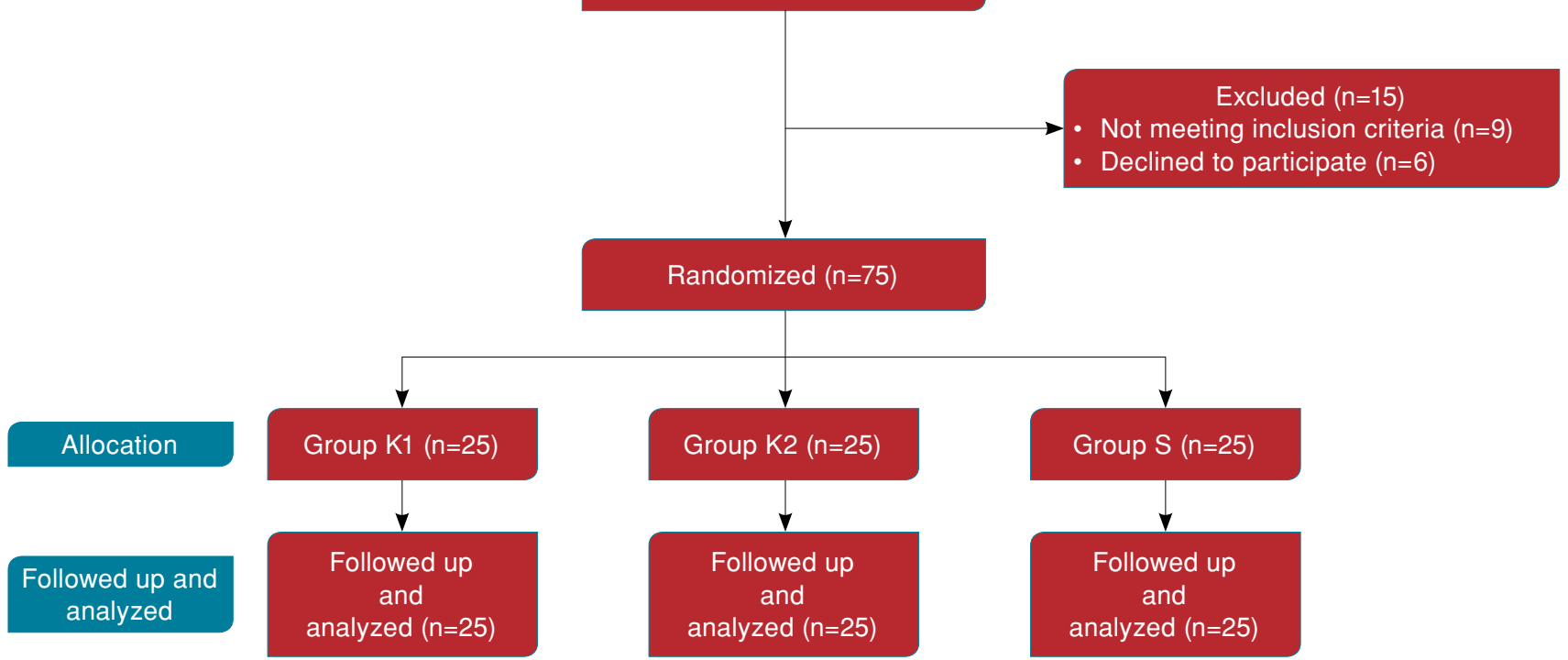


baseline pain scores were recorded preoperatively using VAS pain score as $0=$ no pain and $10=$ the most severe pain imaginable. The study protocol was approved by the Balıkesir University Clinical Research Ethics Committee (2013/041), clinical trials registration number: NCT03955809. A written informed consent was obtained from each patient. The study was conducted in accordance with the principles of the Declaration of Helsinki.

Vascular access was achieved via a 20-gauge needle from the back of the hand $30 \mathrm{~min}$ before the operation, and $0.01 \mathrm{mg} \cdot \mathrm{kg}^{-1}$ intravenous (IV) midazolam was administered for premedication. All patients were monitored with peripheral oxygen saturation, electrocardiogram, noninvasive arterial blood pressure, and heart rate preoperatively. A ProSeal laryngeal mask airway (The laryngeal Mask Company, San Diago, USA) was placed following anesthesia induction with propofol $\left(2-2.5 \mathrm{mg} \cdot \mathrm{kg}^{-1}\right)$ and fentanyl $\left(1 \mu \mathrm{g} \cdot \mathrm{kg}^{-1}\right)$. Anesthesia was maintained with $60 \%$ nitrous oxide in oxygen and $2-2.5 \%$ inspired sevoflurane. Patients were also administered a total of $2 \mu \mathrm{g} . \mathrm{kg}^{-1} \mathrm{IV}$ fentanyl intraoperatively.

After anesthesia induction, a pneumatic tourniquet was applied at $300 \mathrm{mmHg}$ pressure to all patients before surgical incision. All surgical procedures were performed by the same surgeon using a standard surgical technique. At the end of the surgical procedure, patients were randomly divided into three groups (25 patients in each group) with an excel random number generator table. Ketamine (0.5 mg. $\mathrm{kg}^{-1}$ in group K1, $1 \mathrm{mg} \cdot \mathrm{kg}^{-1}$ in group K2) or normal saline (groupS) was administered intraarticularly in a total of $20 \mathrm{~mL}$ volume. In addition to the study protocol, periarticular $10 \mathrm{~mL}$ $0.5 \%$ bupivacaine was administered to patients in all three groups. The study drugs were prepared by an anesthesiologist who did not participate in the evaluation of the patients. The study drug injections were administered through the main arthroscopic portal after completion of the surgery by the surgeon. Periarticular infiltration was performed in peripatellar tissue and into the incision site before application of the dressing and deflation of the pneumatic tourniquet. In all patients, the tourniquet was deflated $10 \mathrm{~min}$ after the application of the drugs. At the end of the surgery, sevoflurane and nitrous oxide were discontinued, the ProSeal laryngeal mask airway was removed, and the durations of the surgery and anesthesia were recorded.

Analgesia in postanesthesia care unit (PACU) was provided by morphine infusion using patientcontrolled analgesia (PCA) pump in all groups.
A PCA pump was set to give $1 \mathrm{mg}$ morphine bolus with a 15-min lock-in time and no basal infusion. Postoperative assessments were performed by an anesthesiologist who was not aware of the study drugs. The time of first analgesic requirement (the first request of the patient by pressing the button), postoperative $30^{\text {th }} \mathrm{min}$, and $1^{\text {st }}, 2^{\text {nd }}, 4^{\text {th }}$, $6^{\text {th }}, 12^{\text {th }}$, and $24^{\text {th }}$ hour analgesia consumption and additional analgesic use were recorded, if applied. In the postoperative period, pain was assessed with VAS at 0 (arriving at the PACU), $30 \mathrm{~min}$, and 1, 2, 4, 6, 12 , and $24 \mathrm{~h}$ both at rest and passive knee movement. Since the ketamine has a half life of 2 to $4 \mathrm{~h}$, pain assessment was limited to $24 \mathrm{~h}$ postoperatively.

Side effects such as nausea \& vomiting, pruritus, and respiratory depression (respiratory rate below $10 / \mathrm{min}$ ), hallucination, urinary retention, and constipation were recorded in the first $24 \mathrm{~h}$ postoperatively.

Patients were discharged when they met the discharge criteria consisting of stable vital signs, ability to intake oral liquid food and to walk, absence of nausea \& vomiting, VAS score under 4, and ability to urinate. The time from arrival to postoperative care unit until discharge was recorded as the duration of discharge.

\section{Statistical analysis}

The primary aim of our study was to compare the differences in postoperative VAS scores among the groups. Considering VAS scores, it was found appropriate to work with 39 subjects in total with 0.40 effect size, $80 \%$ power, and 0.05 error. The power analysis of the research was performed with $\mathrm{G}^{*}$ Power version 3.0.8 software (Heinrich-Heine-Universität, Düsseldorf, Düsseldorf, Germany) and the power of the research was determined.

Categorical data were described using observed frequencies and percentages, and continuous variables were summarized by their means and standard deviations (or medians and interquartile ranges in case normality assumption was not met) with the IBM SPSS version 25.0 software (IBM Corp., Armonk, NY, USA). Chi-square test was used for categorical variables. Normality was assessed using the ShapiroWilk test. One-way analysis of variance was used to compare numeric scale parameters between the three groups. The Kruskal-Wallis test was used to assess the significance of differences between groups where appropriate. Bonferroni adjustment was used for all multiple comparisons to control for type I errors. The statistical evaluation of data in time for three groups was performed with the 


\begin{tabular}{|c|c|c|c|c|c|c|c|}
\hline \multicolumn{8}{|c|}{$\begin{array}{l}\text { TABLE I } \\
\text { Demographic data of patients in groups }\end{array}$} \\
\hline & \multicolumn{2}{|c|}{ Group K1 $(n=25)$} & \multicolumn{2}{|c|}{ Group K2 $(n=25)$} & \multicolumn{2}{|c|}{ Group S (n=25) } & \multirow[b]{2}{*}{$p$} \\
\hline & $\mathrm{n}$ & Mean \pm SD & $\mathrm{n}$ & Mean $\pm S D$ & $\mathrm{n}$ & Mean $\pm S D$ & \\
\hline Age (year) & & $46.2 \pm 11.5$ & & $48.6 \pm 13.3$ & & $45.3 \pm 14.4$ & 0.653 \\
\hline Height (cm) & & $165.2 \pm 11.6$ & & $170.1 \pm 9.4$ & & $165.1 \pm 10.9$ & 0.174 \\
\hline Weight $(\mathrm{kg})$ & & $76.2 \pm 15.4$ & & $78.9 \pm 15.2$ & & $78.0 \pm 11.8$ & 0.796 \\
\hline Sex & & & & & & & 0.256 \\
\hline Male & 9 & & 14 & & 9 & & \\
\hline Female & 16 & & 11 & & 16 & & \\
\hline ASA status & & & & & & & 0.165 \\
\hline 1 & 21 & & 15 & & 17 & & \\
\hline II & 4 & & 10 & & 8 & & \\
\hline Duration of surgery (min) & & $41.9 \pm 20.5$ & & $37.2 \pm 15.2$ & & $49.0 \pm 17.5$ & 0.071 \\
\hline Duration of anesthesia (min) & & $71.1 \pm 19.3$ & & $68.3 \pm 20.1$ & & $77.9 \pm 16.3$ & 0.180 \\
\hline Tourniquet time (min) & & $54.7 \pm 21.8$ & & $50.6 \pm 18.0$ & & $61.9 \pm 17.6$ & 0.119 \\
\hline Meniscectomy location & & & & & & & 0.498 \\
\hline Right & 14 & & 11 & & 15 & & \\
\hline Left & 11 & & 14 & & 10 & & \\
\hline
\end{tabular}

nonparametric Brunner-Langer model (F1-LD-F1) by using a statistical software ( $\mathrm{R}$ software, version 3.5.2, package: nparLD, R Foundation for Statistical Computing, Vienna, Austria; http://r-project.org). In all studies, $p$ values $<0.05$ were considered statistically significant.

\section{RESULTS}

There was no statistically significant difference in patients' demographics, ASA status, meniscectomy location, duration of surgery, anesthesia, tourniquet, or hospital discharge time among the groups (Table I).

Preoperative baseline VAS scores both at rest and during movement were not statistically significantly different among the groups. Visual analog scale scores at rest and movement at the postoperative $0^{\text {th }}$ measurement were significantly lower in group K2 compared to group S but were not significantly different at the other measurement times $(\mathrm{p}<0.05)$ (Figures 2, 3).

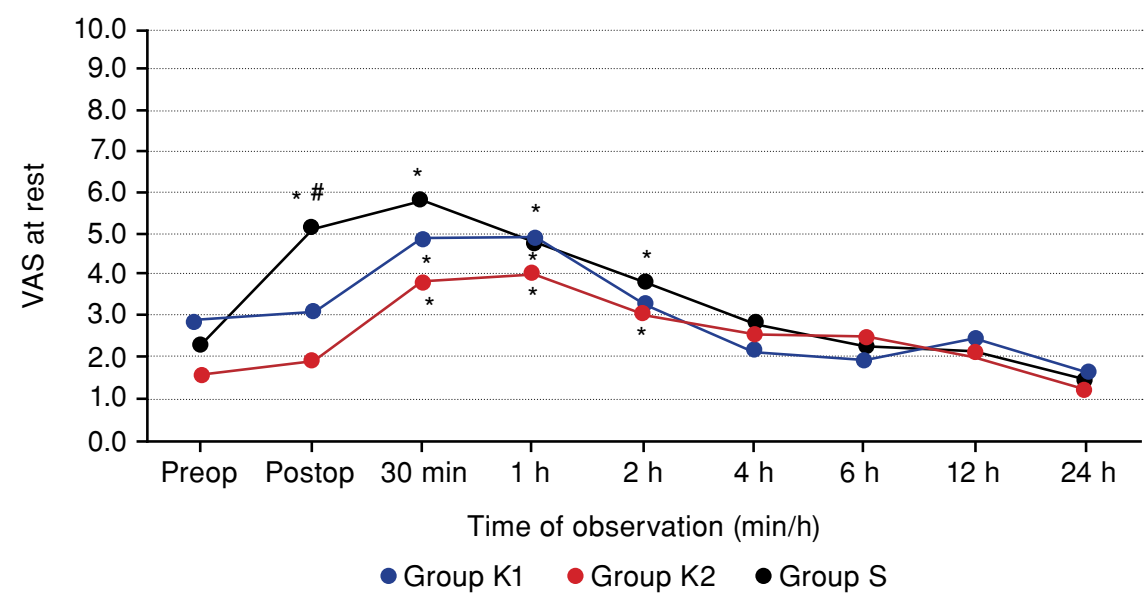

FIGURE 2. Changes in VAS rest scores of groups in time. 


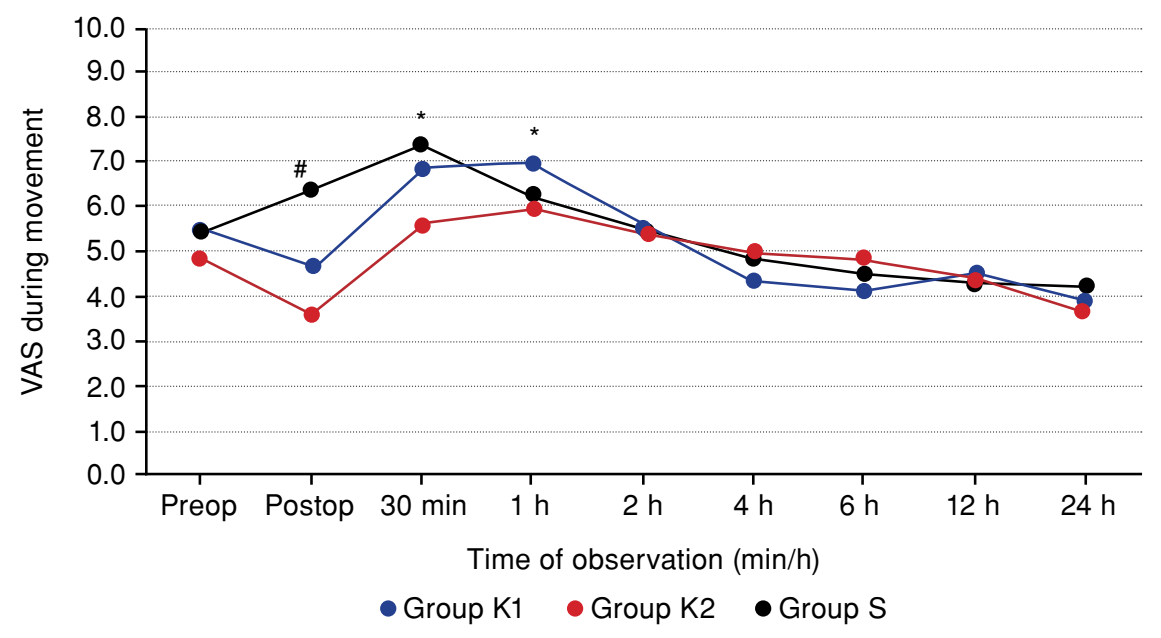

FIGURE 3. Changes in VAS during movement values of groups in time.

\# $\mathrm{p}<0.05$ group $\mathrm{S}$ compared to group $\mathrm{K} 2$; ${ }^{*} \mathrm{p}<0.05$ compared with preoperative baseline VAS during movement score in groups K1 and S; VAS: Visual analog scale; Preop: Preoperative; Postop: Postoperative.

The VAS rest scores in the postoperative period were significantly higher compared to the baseline VAS rest scores at $30 \mathrm{~min}$ and $1 \mathrm{~h}$ in group $\mathrm{K} 1$, at $30 \mathrm{~min}$, and 1 and $2 \mathrm{~h}$ in group $\mathrm{K} 2$, and at postoperative $0 \mathrm{~min}$ $30 \mathrm{~min}$, and 1 and $2 \mathrm{~h}$ in group $\mathrm{S}(\mathrm{p}<0.05)$ (Figure 2).

The VAS movement scores in the postoperative period were significantly higher compared to the baseline VAS movement scores at $30 \mathrm{~min}$ and $1 \mathrm{~h}$ in groups $\mathrm{K} 1$ and $\mathrm{S}(\mathrm{p}<0.05)$. In group $\mathrm{K} 2$, VAS movement scores were similar to the preoperative baseline values at all measurement times (Figure 3).
Total morphine consumption at $24 \mathrm{~h}$ was similar in all groups (6.3 \pm 6.7 in group K1, 7.04 \pm 7.03 in group $\mathrm{K} 2$, and $8.8 \pm 6.15$ in group $S$ ); however, there was a significantly lower morphine consumption in group $\mathrm{K} 2$ compared to groups $\mathrm{K} 1$ and $\mathrm{S}$ at the $30 \mathrm{~min}$, and 1 and $2 \mathrm{~h}$ postoperatively (Figure 4 ).

The first analgesic requirement time was significantly longer in group $\mathrm{K} 1(76.9 \pm 25.2 \mathrm{~min})$ and group K2 $(93.4 \pm 26.1 \mathrm{~min})$ compared to group S $(29.3 \pm 7.1 \mathrm{~min})$ $(\mathrm{p}<0.004)$ (Table II). There was no statistically significant difference between groups K1 and K2.

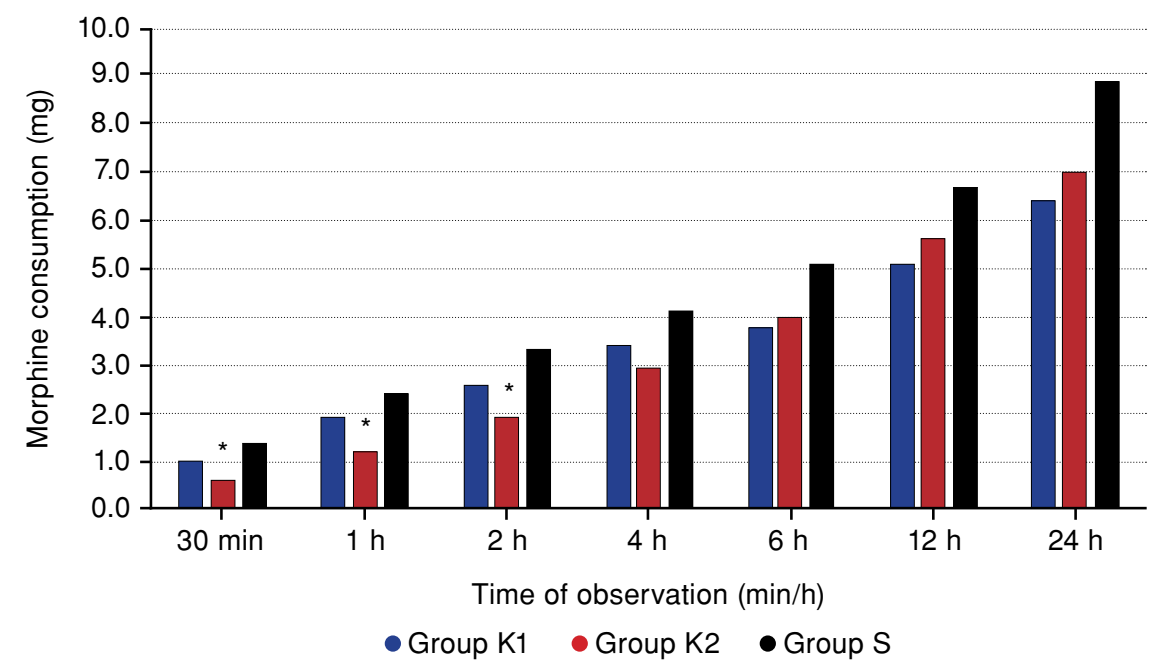

FIGURE 4. Opioid consumption rate of groups in time. Data are presented as mean \pm standard deviation.

${ }^{*} \mathrm{p}<0.05$ group K2 compared to group K1 and group $\mathrm{S}$. 


\begin{tabular}{|c|c|c|c|c|}
\hline \multicolumn{5}{|c|}{ TABLE II } \\
\hline \multirow[b]{2}{*}{ Parameters } & $\mathrm{K} 1(\mathrm{n}=25)$ & $K 2(n=25)$ & $S(n=25)$ & \multirow[b]{2}{*}{$p$} \\
\hline & Mean $\pm S D$ & Mean \pm SD & Mean \pm SD & \\
\hline Time of first analgesic requirement (min) & $76.9 \pm 25.2$ & $93.4 \pm 26.1$ & $29.3 \pm 7.1^{*}$ & 0.004 \\
\hline Time of additional analgesic requirement (min) & $304.3 \pm 131.0$ & $405 \pm 212.5$ & $357 \pm 125$ & 0.995 \\
\hline Length of hospital stay (h) & $27.6 \pm 0.6$ & $27.3 \pm 0.7$ & $27.7 \pm 0.6$ & 0.79 \\
\hline
\end{tabular}

\begin{tabular}{|c|c|c|c|c|c|c|c|}
\hline \multicolumn{8}{|c|}{$\begin{array}{c}\text { TABLE III } \\
\text { rse outcomes }\end{array}$} \\
\hline \multirow[b]{2}{*}{ Parameters } & \multicolumn{2}{|c|}{$K 1 \quad(n=25)$} & \multicolumn{2}{|c|}{$K 2(n=25)$} & \multicolumn{2}{|c|}{$S(n=25)$} & \multirow[b]{2}{*}{$p$} \\
\hline & $\mathrm{n}$ & $\%$ & $\mathrm{n}$ & $\%$ & $\mathrm{n}$ & $\%$ & \\
\hline PONV & 8 & 32 & 5 & 20 & 5 & 20 & 0.518 \\
\hline Urinary retention & 1 & 4 & 4 & 16 & 1 & 4 & 0.196 \\
\hline Pruritus & 0 & 0 & 0 & 0 & 1 & 4 & 0.363 \\
\hline
\end{tabular}

The numbers of patients requiring additional analgesics in groups S, K1, and K2 were 10, 6, and 4 , respectively. Although the number of patients with an additional analgesic requirement was higher in group $\mathrm{S}$, there was no statistically significant difference between the groups $(p=0.148)$.

The incidences of PONV, urinary retention, and pruritus were similar in the three groups. No hallucinations, respiratory depression or constipation were observed in patients (Table III).

\section{DISCUSSION}

In this study, we found that $0.5 \mathrm{mg} \cdot \mathrm{kg}^{-1}$ and 1 mg.kg-1 intraarticular ketamine combined with periarticular $10 \mathrm{~mL} 0.5 \%$ bupivacaine administered for postoperative pain management after arthroscopic meniscectomy provided similar analgesic efficacy in the postoperative period and prolonged the time to first analgesic requirement. Also, $1 \mathrm{mg} \cdot \mathrm{kg}^{-1}$ intraarticular ketamine decreased opioid consumption in the early postoperative period..$^{[11]}$

Intrarticular analgesic injection for postoperative pain relief after arthroscopic knee surgery is a simple technique which does not need any specialization or special equipment. NMDA receptor antagonists may have antihy peralgesic effects when administered intraarticularly because NMDA receptors are expressed on chondrocytes and synoviocytes..$^{[12]}$ Although ketamine is a NMDAR antagonist, there are controversial findings about its efficacy as an analgesic for postoperative pain after arthroscopic knee surgery after intraarticular administration. ${ }^{[4,7,73]}$

Analgesic effect of single intraarticular drugs is short, but efficacy can be prolonged and increased with combining drugs. ${ }^{[14,15]}$ Intraarticular administration of ketamine in combination with local anesthetics (LAs) provides more effective analgesia while LAs have been reported to have detrimental effects on the articular cartilage and chondrocytes. ${ }^{[16]}$ Thus, the periarticular infiltration of LAs instead of intraarticular administration is preferred nowadays. ${ }^{[17]}$ Baverel et al. ${ }^{[18]}$ recommended that periarticular LA infiltration can be performed as part of multimodal analgesia for ambulatory arthroscopic knee surgery. Therefore, in our study, we used two different doses of intraarticular ketamine combined with periarticular $10 \mathrm{~mL} 0.5 \%$ bupivacaine for all our patients. We consider that periarticular LA application also contributed to postoperative pain levels in all study patients.

Isik et al. ${ }^{[14]}$ combined $50 \mathrm{mg} \quad-0.25 \%$ levobupivacaine with $1 \mathrm{mg} \cdot \mathrm{kg}^{-1}$ or $0.5 \mathrm{mg} \cdot \mathrm{kg}^{-1}$ ketamine for intraarticular administration and observed significantly lower VAS scores at 1,2 . and $4 \mathrm{~h}$ postoperatively compared to the control group. Batra et al. ${ }^{[15]}$ demonstrated that VAS scores at one to $4 \mathrm{~h}$ postoperatively were significantly higher after intraarticular $1 \mathrm{mg} \cdot \mathrm{kg}^{-1}$ ketamine alone 
as compared to intraarticular bupivacaine and combination of bupivacaine and ketamine. In our study, VAS scores at rest and movement of patients who received $1 \mathrm{mg} \cdot \mathrm{kg}^{-1}$ ketamine intraarticularly combined with periarticular $10 \mathrm{~mL} 0.5 \%$ bupivacaine were significantly lower than only periarticular bupivacaine in only early postoperative period. Since the affinity of ketamine to opioid receptors is poor, the analgesic effect of ketamine may be insufficient to provide sufficient duration of analgesia. ${ }^{[19]}$ As in other studies, we evaluated the effect of intraarticular ketamine administration at doses of $1 \mathrm{mg} \cdot \mathrm{kg}^{-1}$ and below. Thus, further studies are needed to evaluate the effectiveness of higher doses of ketamine intraarticularly.

Various doses between 0.25 to 1 mg. kg-1 of intraarticular ketamine alone or as adjuvant have been used for postoperative pain management after arthroscopic knee surgery. However, the results about the required dose and volume for administration are controversial. Huang et al. ${ }^{[7]}$ found that $5 \mathrm{~mL}$ of $0.5 \mathrm{mg} \cdot \mathrm{kg}^{-1}$ intraarticular ketamine had no beneficial effect on pain scores in the first $24 \mathrm{~h}$ postoperatively, while Borner et al. ${ }^{[10]}$ demonstrated that $0.25 \mathrm{mg} / \mathrm{kg}$ intraarticular ketamine in a total volume of $10 \mathrm{~mL}$ effectively decreased pain scores and reduced analgesic requirement. We found that although $0.5 \mathrm{mg} \cdot \mathrm{kg}^{-1}$ intraarticular ketamine in $20 \mathrm{~mL}$ volume combined with periarticular $10 \mathrm{~mL} 0.5 \%$ bupivacaine prolonged the time to first analgesic requirement, it had no effect on pain scores and analgesic consumption, while $1 \mathrm{mg} \cdot \mathrm{kg}^{-1}$ intraarticular ketamine significantly reduced VAS scores at rest and movement and morphine consumption in the early postoperative period. We believe that the difference in analgesic efficacy may be due to the difference in volume in addition to the dose.

Salman et al. $^{[8]}$ demonstrated that 1 mg.kg-1 intraarticular ketamine provided higher analgesic efficacy, earlier mobilization, and less additional analgesic requirement in arthroscopic meniscectomy. Although the number of patients with additional analgesic requirement in our study is not significantly different between groups, intraarticular ketamine use causing less additional analgesic requirement may provide an advantage in the early periods during which mobility is important.

The systemic use of NMDAR antagonists can often cause serious side effects such as psychotic adverse effects including psychomimetic effects, drowsiness, nightmares, hallucinations, and delirium, ${ }^{[5,20]}$ There is a concern that high doses of intraarticular ketamine, which is a NMDAR antagonist, may cause side effects similar to those observed after systemic use. In response, Rosseland et al. ${ }^{[21]}$ demonstrated that serum ketamine concentrations after intraarticular injections were lower than intramuscular administration. The low incidence of adverse effects may be related to the lack of vessels in the articular surface and the relatively small dose of ketamine administered. Batra et al. ${ }^{[15]}$ showed no significant differences between the intraarticular administration of ketamine group and control group with regard to central side effects. However, Salman et al. ${ }^{[8]}$ reported that the incidence of hallucinations in the intraarticular administration of ketamine group was significantly higher than that in the control group. In our study, we did not observe any side effects after $0.5 \mathrm{mg} \cdot \mathrm{kg}^{-1}$ and $1 \mathrm{mg} \cdot \mathrm{kg}^{-1}$ doses of intraarticular ketamine.

Postoperative pain after arthroscopy can be variable due to multiple factors such as type and duration of surgery, experience of the surgeon, regional or general anesthesia, premedication, volume of the injected analgesic agent, and timing of intraarticular injection. Beside these factors, the intensity and duration of pain before surgery may also have an impact. ${ }^{[22]}$ Most of these factors have been standardized in our study, while the lack of evaluation of preoperative pain intensity and duration is our limitation. Also, we did not assess the degree of osteoarthritic changes preoperatively or the type of meniscectomy or localization of the meniscus lesions.

In conclusion, $0.5 \mathrm{mg} \cdot \mathrm{kg}^{-1}$ and $1 \mathrm{mg} \cdot \mathrm{kg}^{-1}$ intraarticular ketamine combined with periarticular $10 \mathrm{~mL} 0.5 \%$ bupivacaine administered for postoperative pain management after arthroscopic meniscectomy provided similar analgesic efficacy in the postoperative period and prolonged the time to first analgesic requirement. Also, $1 \mathrm{mg} \cdot \mathrm{kg}^{-1}$ intraarticular ketamine decreased opioid consumption in the early postoperative period.

\section{Declaration of conflicting interests}

The authors declared no conflicts of interest with respect to the authorship and/or publication of this article.

\section{Funding}

The authors received no financial support for the research and/or authorship of this article.

\section{REFERENCES}

1. Atik OŞ. Should degenerative horizontal tear of the medial meniscus be treated with surgery? Eklem Hastalik Cerrahisi 2018;29:63-4.

2. Elsharnouby NM, Eid HE, Abou Elezz NF, Moharram AN. Intraarticular injection of magnesium sulphate and/or bupivacaine for postoperative analgesia after arthroscopic knee surgery. Anesth Analg 2008;106:1548-52. 
3. Caparrini C, Miniati I, Ponti M, Baldini A. Perioperative pain management in fast-track knee arthroplasty. Acta Biomed 2017;88:139-44.

4. Pan L, Shen Y, Ma T, Xue H. The efficacy of ketamine supplementation on pain management for knee arthroscopy: A meta-analysis of randomized controlled trials. Medicine (Baltimore) 2019;98:e16138.

5. Petrenko AB, Yamakura T, Baba H, Shimoji K. The role of $\mathrm{N}$-methyl-D-aspartate (NMDA) receptors in pain: a review. Anesth Analg 2003;97:1108-16.

6. Yu XM, Sessle BJ, Haas DA, Izzo A, Vernon H, Hu JW. Involvement of NMDA receptor mechanisms in jaw electromyographic activity and plasma extravasation induced by inflammatory irritant application to temporomandibular joint region of rats. Pain 1996;68:169-78.

7. Huang GS, Yeh CC, Kong SS, Lin TC, Ho ST, Wong CS. Intraarticular ketamine for pain control following arthroscopic knee surgery. Acta Anaesthesiol Sin 2000;38:131-6.

8. Salman N, Olgunkeleş B, Bektaş U, Güner D, Bektas M, Ay Ş, et al. Effects of intraarticular tramadol, magnesium and ketamine on postoperative pain in arthroscopic meniscectomy. Rev Bras Anestesiol 2019;69:35-41.

9. Ayoglu H, Altunkaya H, Bayar A, Turan IO, Ozer Y, Ege A. The effect of intraarticular combinations of tramadol and ropivacaine with ketamine on postoperative pain after arthroscopic meniscectomy. Arch Orthop Trauma Surg 2010;130:307-12.

10. Borner M, Bürkle H, Trojan S, Horoshun G, Riewendt HD, Wappler F. Intra-articular ketamine after arthroscopic knee surgery. Optimisation of postoperative analgesia. Anaesthesist 2007;56:1120-7.

11. Atik OŞ. Is there something new and interesting in my article? Eklem Hastalik Cerrahisi 2019;30:69.

12. Lawand NB, Willis WD, Westlund KN. Excitatory amino acid receptor involvement in peripheral nociceptive transmission in rats. Eur J Pharmacol 1997;324:169-77.

13. Dal D, Tetik O, Altunkaya H, Tetik O, Doral MN. The efficacy of intra-articular ketamine for postoperative analgesia in outpatient arthroscopic surgery. Arthroscopy 2004;20:300-5.

14. Isik C, Demirhan A, Yetis $T$, Okmen $K$, Sarman $H$, Tekelioglu UY, et al. Efficacy of intraarticular application of ketamine or ketamine-levobupivacaine combination on post-operative pain after arthroscopic meniscectomy. Knee Surg Sports Traumatol Arthrosc 2015;23:2721-6.

15. Batra YK, Mahajan R, Bangalia SK, Nagi ON, Dhillon MS. Bupivacaine/ketamine is superior to intra-articular ketamine analgesia following arthroscopic knee surgery. Can J Anaesth 2005;52:832-6.

16. Piper SL, Kramer JD, Kim HT, Feeley BT. Effects of local anesthetics on articular cartilage. Am J Sports Med 2011;39:2245-53.

17. Toftdahl K, Nikolajsen L, Haraldsted V, Madsen F, Tønnesen EK, Søballe K. Comparison of peri- and intraarticular analgesia with femoral nerve block after total knee arthroplasty: a randomized clinical trial. Acta Orthop 2007;78:172-9.

18. Baverel L, Cucurulo T, Lutz C, Colombet, Cournapeau J, Dalmay F, et al. Anesthesia and analgesia methods for outpatient anterior cruciate ligament reconstruction. Orthop Traumatol Surg Res 2016;102:S251-S5.

19. Hirota K, Lambert DG. Ketamine: its mechanism(s) of action and unusual clinical uses. Br J Anaesth 1996;77:441-4.

20. Xu B, Wang Y, Zeng C, Wei J, Li J, Wu Z, et al. Analgesic efficacy and safety of ketamine after total knee or hip arthroplasty: a meta-analysis of randomised placebocontrolled studies. BMJ Open 2019;9:e028337.

21. Rosseland LA, Stubhaug A, Sandberg L, Breivik H. Intraarticular (IA) catheter administration of postoperative analgesics. A new trial design allows evaluation of baseline pain, demonstrates large variation in need of analgesics, and finds no analgesic effect of IA ketamine compared with IA saline. Pain 2003;104:25-34.

22. Brill S, Plaza M. Non-narcotic adjuvants may improve the duration and quality of analgesia after knee arthroscopy: a brief review. Can J Anaesth 2004;51:975-8. 